\title{
Sclerotium hydrophilum en cultivos de arroz de Argentina
}

\author{
Susana A. Gutiérrez ${ }^{1}$
}

\begin{abstract}
${ }^{1}$ Cátedra de Fitopatología, Facultad de Ciencias Agrarias, UNNE. Sargento Cabral 2131, 3400. Corrientes, Argentina. suarroz@ yahoo.com.ar Data de chegada: 01/11/2005. Aceito para publicação em: 20/07/2006.
\end{abstract}

En la región nordeste de la Argentina (NEA), las vainas foliares y tallos de plantas de arroz, presentan síntomas de enfermedades producidas por hongos de los géneros Rhizoctonia y Sclerotium. El género Rhizoctonia comprende especies que integran el complejo causal del manchado de vainas foliares del arroz ( $R$. solani, $R$. circinata var. oryzae, $R$. circinata var. zeae, $R$. oryzae-sativae y $R$. circinata var. circinata), presentes en la región con una alta prevalencia en los arrozales del NEA. En cuanto al género Sclerotium, se destaca S. oryzae, causante de la podredumbre del tallo de arroz.

Durante las últimas campañas agrícolas, se observó a un hongo del género Sclerotium asociado a vainas foliares de plantas de arroz próximas a maduración, en las localidades de Empedrado, Itá Ibaté y Mercedes (provincia de Corrientes) y San Javier (provincia de Santa $\mathrm{Fe}$ ), Argentina. Ante la presencia de una nueva enfermedad, el objetivo de este trabajo fue determinar su etiología y evaluar su patogenicidad. El hongo fue aislado en medio de cultivo APG (agar papa glucosa). Se estudiaron sus características culturales y morfométricas. La patogenicidad se probó inoculando vainas foliares de plantas de arroz de la variedad Taim, de 70 días de edad, con trozos de micelio y esclerocios.

En lesiones de color castaño oscuras, irregulares, sobre vainas foliares de arroz variedades Taim, Supremo 1, Supremo 13 y Diamante, se identificó a Sclerotium hydrophilum Saccardo (Fig. 1). La sintomatología observada, así como las características morfométricas coincidió con la bibliografía (Ou, S.H. Rice diseases. CMI, Kew, Surrey, England, 1985. 380 p.). En APG, el hongo desarrolló colonias blancas de crecimiento rápido, cuyos esclerocios se formaron a los 4 días después de la siembra. Dichos cuerpos son globosos a irregulares, lisos, de 300 a 600 um, de color blanco al inicio de su formación, luego castaño rojizo y a la madurez, de color castaño oscuro a negros. En las plantas inoculadas, los síntomas se manifestaron a los 5 días después de la inoculación, lográndose el reaislamiento del hongo. Los daños observados en las pruebas de patogenicidad fueron leves, coincidiendo con lo obtenido por Cedeño et al, en Venezuela, quienes señalaron que los mismos carecían de importancia económica (Cedeño, L.; Nass, H.; Carrero, C.; Cardona, R.; Rodríguez Aleman, L. Sclerotium hydrophilum en arroz en Venezuela. Fitopatología Venezolana v.10, p.9-12, 1997).

Sclerotium hydrophilum es considerado un parásito débil con características de saprófito facultativo, de aparición frecuente en plantas acuáticas y semiacuáticas de las regiones templada y tropical. Fue aislado de 19 géneros de plantas pertenecientes a 6 familias monocotiledóneas y 3 dicotiledóneas. El denominador común que caracteriza a este amplio rango de hospedantes es el hábitat húmedo

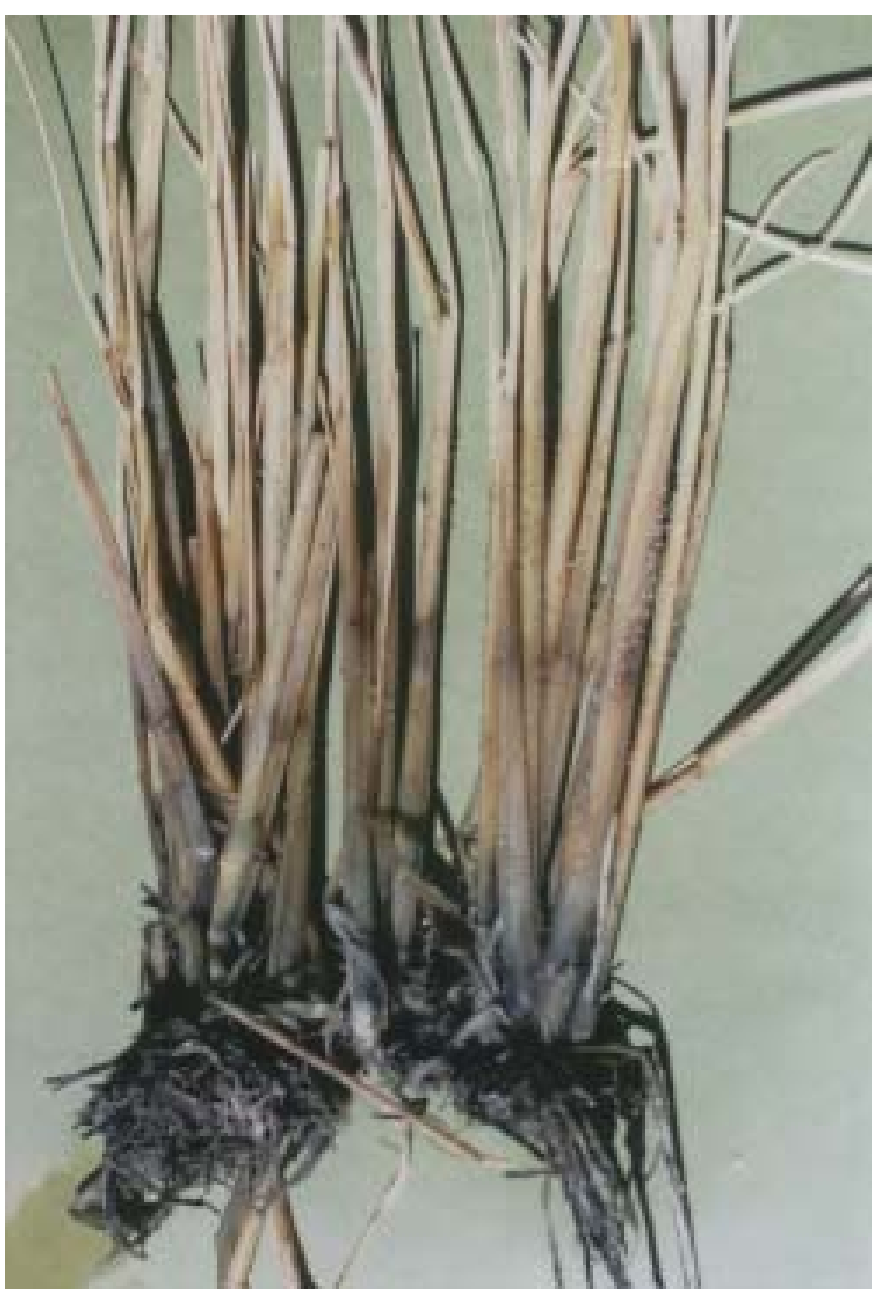

Figura 1. Síntomas en vainas foliares de arroz. Desarrollo de esclerocios en diferentes grados de maduración sobre los tejidos enfermos.

en el cual ellos se presentan. Según Punter et al, $S$. oryzae y $S$. hydrophilum, con frecuencia se presentan asociados en los tejidos enfermos de plantas de arroz cultivado y silvestre (Punter, D.; Reid, J.; Hopkin, A.A. Notes on sclerotium-forming fungi from Zizania aquatica (wildrice) and other hosts. Mycologia v.76, n.4, p.722-732, 1984). Esto es coincidente con lo observado en nuestro país, en las localidades de detección de la enfermedad. Esta es la primera información sobre la presencia de S. hydrophilum afectando arroz en Argentina. 